\section{Intentional vocabulary learning from watching DVDs with subtitles: A case study of an 'average' learner of French}

Garnier, Mélodie $\square$

University of Nottingham, United-Kingdom (melodie.garnier@nottingham.ac.uk)

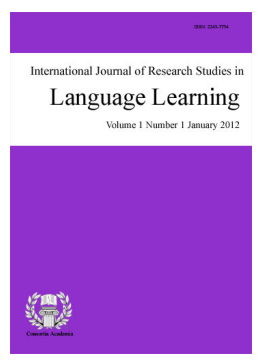

ISSN: $2243-7754$ Online ISSN: 2243-7762

OPEN ACCESS

\title{
Abstract
}

Watching films with subtitles is a popular activity among language learners, but little research has sought to thoroughly examine its potential impact on vocabulary uptake and retention. In particular, there is a lack of longitudinal studies involving intentional rather than incidental learning. This paper seeks to address this gap by investigating the vocabulary gains of a post-beginner learner of French from watching the same film once a week for two months in the reversed subtitling condition (L1 audio and L2 subtitles). The results are encouraging in that the participant continually learned new words after each viewing, while retaining all the words learned in previous weeks. However the very poor uptake rate per hour after the first two viewings suggests that such an activity is not worthwhile beyond a few hours spent on watching the same film. The relationship between repetition and word acquisition/retention was not straightforward, and was probably overshadowed by word-based (e.g. word class) and affective (e.g. motivation) factors. Nevertheless, if learners enjoy watching subtitled films anyway, enough vocabulary acquisition accrues from one or two viewings to recommend this activity as a useful supplement to formal instruction.

Keywords: vocabulary acquisition; intentional learning; watching films/movies with subtitles 


\section{Intentional vocabulary learning from watching DVDs with subtitles: A case study of an 'average' learner of French}

\section{Introduction}

Audiovisual material is becoming an increasingly popular tool in foreign language learning. It is a convenient way to supplement the learning done in the classroom, and it enables learners to be exposed to native-speaker input in meaningful and communicative situations. Watching films or TV programs in a foreign language is very often regarded as a pleasant activity and is becoming increasingly available via DVDs and the Internet. Despite this, the vocabulary learning potential of watching films, especially with subtitles, has not yet been adequately explored. The few studies which investigated vocabulary learning from watching films were typically interested in comparing different subtitle viewing conditions, and therefore were rather short and did not include any further analysis into the learned words themselves. They were cross-sectional instead of longitudinal, therefore missing out on the detection of cumulative vocabulary learning. They also involved participants who had no deliberate aim of learning vocabulary whilst watching the film, so the learning was incidental. However, evidence from previous research on incidental learning (notably from reading: Horst, Cobb, \& Meara, 1998; Hulstijn, 1992; Pellicer-Sánchez \& Schmitt, 2010) shows that without any deliberate attention to form (which is overlooked in the case of incidental learning where the only focus is on meaning), limited uptake and retention occurs. Therefore, the starting point of the present case study was to investigate vocabulary uptake and retention from watching films with subtitles when words in the subtitles are deliberately focused on, i.e. intentional vocabulary learning. In addition, evidence from previous research (e.g. Horst \& Meara, 1999; Saragi, Nation, \& Meister, 1978) shows that repetition is a key factor in vocabulary learning, but this has been based largely on reading studies. I will investigate the benefits and limitations of repetition in audiovisual materials. In particular, I will explore whether there is a point after which words are particularly likely to be learned, and/or whether there is a point after which further repeated viewings become ineffective.

\section{Background}

\subsection{Advantages of reversed subtitling}

A great deal of research on watching foreign films or TV programs with subtitles has been conducted with the goal of comparing the relative efficiency of various subtitling conditions on language learning. On the whole, previous research shows that, for adults, the reversed subtitling mode (i.e. native language in the soundtrack and L2 in the subtitles) resulted in more vocabulary acquisition than the normal subtitling mode (L2 in soundtrack and L1 subtitles) (d'Ydewalle \& Pavakanun, 1996, 1997; Pavakanun \& d'Ydewalle, 1992), although exceptions were also found (d'Ydewalle \& Pavakanun, 1995). The visual dimension seems to outperform the auditory dimension and to facilitate vocabulary learning. The reading of subtitles appears automatic by most viewers (d'Ydewalle \& Gielen, 1992), and so the major involvement in the activity seems to be the processing of the subtitles, which explains the better processing of the foreign language in the reversed subtitling mode (d'Ydewalle \& Pavakanun, 1997). Lambert, Boehler, and Sidoti (1981) also compared various combinations of audio and visual input, and found that subjects in the reversed subtitling condition did significantly better on input comprehension, contextual meaning and spelling posttests than subjects in any other condition. Holobow, Lambert, and Sayegh (1984) similarly reached the conclusion that reversed subtitling was the most efficient in terms of comprehension. However, the exception to this is children, who seem to favour the auditory dimension, which according to d'Ydewalle and Van de Poel (1999) can potentially be explained by differences in cognitive capacity. 


\subsection{Advantages of visual imagery}

Furthermore, a great deal of research has showed the benefits of visual associations and imagery on memory. This is what Paivio (1986) famously called dual coding, which can be defined as the linkage between two representational systems: verbal and imagery. Representations in one system can potentially activate those in the other. In the case of foreign language learning, according to Paivio, the implications are that words learned in association with nonverbal referents (i.e., imagery) will result in richer and more meaningful referential interconnections, and thus better language recall. Similarly, according to d'Ydewalle and Van de Poel (1999), subtitling has the advantage of providing the viewer with three different channels of information: the pictorial information, the original soundtrack, and the translation of the text in the subtitles, each one potentially enhancing the processing of the other two. This in turn could potentially enhance incidental language acquisition.

\subsection{Incidental vocabulary learning}

Danan (1992) conducted a study examining how subtitled video programs could enhance vocabulary learning in three viewing modes (L2 audio only, standard subtitling, and reversed subtitling). She tested vocabulary recall for beginning and intermediate French college students after watching a five-minute video excerpt of a French program. Whilst reversed subtitling again proved to be the most successful condition, she suggests that watching films with subtitles can promote receptive acquisition of vocabulary as demonstrated by results on her translation tests, and also enables learners to establish an initial form-meaning link which associated imagery should help to reinforce. The participants in her study were able to comprehend the vocabulary items even when presented out of context, which according to Danan suggests that the same items are likely to be recognised in new contexts. Finally, she advocates the use of both reversed and bimodal (L2 audio and subtitles) subtitling conditions as a useful complement to explicit instruction, the former to allow students some initial passive knowledge and the latter to further this knowledge. She also advocates enough subsequent repetition for the vocabulary to become ultimately productive.

In relation to incidental vocabulary learning, Pavakanun and d'Ydewalle (1992) and d'Ydewalle and Pavakanun $(1995,1996,1997)$ demonstrated the positive impact of watching short subtitled television programs for adult participants (in this case, 15-minute long cartoons). In both normal and reversed subtitling conditions, immediate vocabulary tests showed substantial learning, in contrast to syntax and grammar tests. However no posttest was carried out to test for durable learning. On the other hand, d'Ydewalle and Van de Poel (1999) found modest learning by children watching a subtitled movie, but their study involved very limited exposure (10 minutes) and immediate testing only. Consequently they argued for the need for longitudinal studies assessing cumulative effects of exposure, along with posttests in order to assess long-term retention.

Bisson, Van Heuven, Conklin, and Tunney (2012) investigated L2 incidental vocabulary acquisition from watching films using an auditory vocabulary test at the meaning recognition level, but found no evidence of vocabulary acquisition. The authors suggest this might be due to the limited exposure in the study (25 min), which again argues for the need for longer-term studies with sustained exposure. They also suspected that the measure they used might not have been sensitive enough to capture the acquisition from such a short study period.

As for the individual strategies used by learners when watching captioned video, Vanderplank (1990) examined how learners of English used captions over a three-month period. He found that participants who did not take notes while watching captioned videos did not retain the specific language used in the videos and did not produce very accurate language on subsequent comprehension exercises. He concluded that attention to both form and meaning is necessary for intake and long-term retention.

\subsection{Intentional vocabulary learning}

Until now most research on vocabulary acquisition and learning words from context has focused on written 
contexts, partly due to the importance of reading, and partly due to the comparative ease of researching written vs. spoken texts (see van Zeeland and Schmitt, under review, for one of the few exceptions). Furthermore, the few studies focusing on vocabulary acquisition from watching films or TV programs, as seen above, have focused on incidental learning. However it is possible to watch films with the deliberate intention of learning words, and indeed previous research suggests this might be a more promising option than purely incidental learning. Milton (2008) emphasises two conditions to make informal learning such as movie watching a worthwhile activity for building good vocabularies: it should involve a focus on form - this echoes findings from other studies - and the learner should genuinely be willing to be involved in the tasks and learn the language. The first condition should involve a focus on word forms, and this means potentially pausing the film at times when the subtitles are simply too fast for the form of the word to be noticed. The second condition can be facilitated if learners choose the movies they wish to see. For Milton, a major advantage of informal activities is that they are likely to involve a large and varied vocabulary so that learners can learn each time they return to them, even after having spent many hours on the same activity. That is, if the same activity is repeated week after week, the repetition and recycling of the vocabulary will have a positive impact on acquisition.

To the author's knowledge, Milton (2008) is the only study that has investigated intentional vocabulary learning from watching films with subtitles. He carried out a case study on vocabulary uptake from a DVD film with subtitles involving one English-speaking participant who watched a DVD of Xena Warrior Princess with English audio and Greek subtitles once a week for four weeks. The film could be paused anytime, and even though the film lasted about 100 minutes, the weekly activity lasted approximately 2.5 hours with pauses for reading and rewinding. A pretest identifying known and unknown words in the subtitles was administered. Among the 382 unknown lemmatised types occurring only once in the subtitles, 100 were selected for testing which was in the form of a Yes/No checklist test. The rate of acquisition was substantial: about 40 words per session, or around 16 per hour of study. Nevertheless, Milton raises the concern that this case study might not reveal what could typically be achieved in reality. The subject involved was an exceptionally good learner, very able, and highly motivated. It seems therefore necessary to extend this experiment to less ideal learners and thereby assess the individual variation aspect. The present case study is a first step towards this goal, focusing on what might be considered a more 'average' second language learner.

\subsection{Research questions}

This paper aims to assess the impact of watching a film with L1 audio and L2 subtitles on vocabulary acquisition and retention by answering three main questions:

1) How much vocabulary can be acquired from watching the same film repeatedly for 8 weeks, and how much of this learning is durable, i.e. can be retrieved after a month?

2) What learning rates can be achieved per viewing and per hour, and how do these compare with the incidental learning results reported from reading?

3) To what extent does repetition have an impact on the likelihood of words being learned?

\section{The study}

\subsection{Participant}

My participant (Neil)1 was a 21-year-old British undergraduate student at the time of the experiment. He studied French up to GCSE and International Baccalaureate level, but considers himself a very average learner and reported getting rather poor grades during his school instruction. By the time he started the current experiment he had stopped learning French for three years, and despite occasional encounters, his exposure to French was virtually nonexistent. It is unknown how much vocabulary he gained from his French instruction, but 
it is very probable that much of vocabulary he accumulated during his school years had been forgotten. Overall, he could not truly be considered a beginner, but his general proficiency was quite low.

Neil had a keen interest in the French language and culture in general, but also strong affective reasons for wanting to improve his French. On starting the experiment, he appeared very enthusiastic at the prospect of increasing his vocabulary knowledge, and he welcomed the activity as an opportunity to do so. He was made fully aware of the purpose of the study, and of the weekly tests he would have to complete to check on his progress. In short, his motivation appeared to be strong.

\subsection{Materials}

A major condition of success for the present activity was that Neil would have a genuine interest in watching the film, and he personally chose Toy Story 3. It was played with English audio and French subtitles. One reason for this choice was the superiority of reversed subtitling as found in many previous studies. Reversed subtitling could also help Neil segment what might otherwise have been an incomprehensible stream of speech, and to identify word boundaries (Winke, Gass, \& Sydorenko, 2010) - especially since the French language does not typically feature strong stresses or intonation features which can be helpful in sequencing words or sentences. Another reason concerns making the mode of the learning condition (written subtitles) and the assessment (written test) consistent. It should also be noted that although the bimodal input condition (L2 audio and subtitles) has been shown advantageous in previous studies, even for beginners (Danan, 1992), the level of the participant in the present study was considered too low for the bimodal input condition to be adequate for the chosen movie.

\subsection{Instruments}

The subtitles were analysed via Lextutor (http://www.lextutor.ca), with the counting unit of word families. Overall 929 word families were found and successively presented to Neil for him to check those he already knew. The result was 415 unknown word families. From those, I selected 100 to be included on the test, ensuring I included words with a variety of repetition rates throughout the film (range=1-39), in order to assess the impact of repetition on acquisition. In reference to Horst et al.'s (1998, p. 215) suggestion that

\section{'sizeable learning gains can be expected to occur consistently for items that are repeated eight times or more, [...] with a large amount of variation in gains on words that are repeated five times or less',}

I could expect a large number of words to be learned, since even words occurring only once in each viewing occurred 8 times by the end of the experiment. A Checklist + Translation format was chosen in order for Neil to quickly report on his knowledge of the words week after week by checking all the words he considered as known. For each of the 100 French target words he checked, a meaning had to be provided in the form of an English translation. Therefore, the level of knowledge being tested was meaning recall, i.e. the meaning of the word had to be retrieved by seeing its form. Checked but incorrectly translated words were considered as still unknown.

\subsection{Procedure}

Before the experiment, Neil was made aware of the importance of focusing explicitly on the subtitles, and was strongly encouraged to pause the film whenever needed, since the process of briefly seeing a word did not seem an efficient way of retaining it judging from the literature. Neil watched Toy Story 3 once a week for a two-month period, which amounted to a total of eight viewings. On the whole, he reported spending around two and a half hours doing the activity each week (with the film lasting one and a half hours, plus one hour devoted to pauses).

Immediately after each viewing he was given the vocabulary test. These were new blank tests each week so that he could not be influenced by what he had checked and written in the previous tests. In order to assess the long-term impact of the activity, he was given a delayed posttest four weeks after the last viewing (same test). 
Garnier, M.

On this occasion he did not watch the film prior to completing the test.

Immediately after completing the vocabulary test each week, he was asked to record his thoughts in a diary, ranging from thoughts on the activity and its potential impact, to difficulties related to the subtitles, to his current state of motivation. This additional component added a qualitative dimension to the experiment and was carried out in the hope of gaining valuable insights from the participant that could have been impossible to grasp in a strictly quantitative analysis.

\section{Results and Discussion}

\subsection{Weekly vocabulary acquisition and retention}

At the end of the eighth viewing, Neil knew the meanings of 27 word families out of the 100 selected (or 43 lemmas if we accept Milton's (2009) rule of thumb to multiply word families by 1.6 to convert them into lemmas) (Table 1). It is only slightly better than in Milton's (2008) experiment in which 41 lemmas had been learned, but which lasted half as long. If we extend this estimate to the 415 unknown word families identified in the pretest, it means Neil learned 112 word families overall $(27 \mathrm{x} 4.15)$ from the unknown words in the film subtitles $(27 \%)$. Therefore, as expected, Neil's vocabulary knowledge progressively increased and nearly every viewing enabled him to gain new words. But what is particularly worth mentioning is that Neil was constantly acquiring new words whilst remembering what was previously learned. That is, once a word had been checked and correctly translated, it remained known throughout the rest of the weekly tests (the only exception is one word forgotten from week 6 to week 7, but which was checked again in week 8). Therefore the activity seemed to promote solid and lasting learning of words. Unfortunately, this stability of learning also applied to some words that were incorrectly translated from the start and which remained that way through the study, even though the context of the film should have made these 'mismatches' obvious (e.g. secours [help] in the test was consistently translated as "shake" (secouer in French).

Table 1

Number of checked and correctly translated words per week and in the posttest

\begin{tabular}{|c|c|c|c|c|c|c|c|c|c|}
\hline & $\begin{array}{l}\text { Week } \\
1\end{array}$ & $\begin{array}{l}\text { Week } \\
2\end{array}$ & $\begin{array}{l}\text { Week } \\
3\end{array}$ & $\begin{array}{l}\text { Week } \\
4\end{array}$ & $\begin{array}{l}\text { Week } \\
5\end{array}$ & $\begin{array}{l}\text { Week } \\
6\end{array}$ & Week 7 & $\begin{array}{l}\text { Week } \\
8 \\
\end{array}$ & $\begin{array}{l}\text { Week 12 } \\
\text { Posttest }\end{array}$ \\
\hline $\begin{array}{l}\text { Words } \\
\text { known } \\
(\operatorname{Max}=100)\end{array}$ & 6 & 11 & 11 & 14 & 19 & 21 & 23 & 27 & 20 \\
\hline $\begin{array}{l}\text { Change } \\
\text { from } \\
\text { previous } \\
\text { week }\end{array}$ & & $\begin{array}{l}+5 \\
\text { new } \\
\text { words }\end{array}$ & +0 & $\begin{array}{l}+3 \\
\text { new } \\
\text { words }\end{array}$ & $\begin{array}{l}+5 \\
\text { new } \\
\text { words }\end{array}$ & $\begin{array}{l}+2 \\
\text { new } \\
\text { words }\end{array}$ & $\begin{array}{l}+3 \\
\text { new words } \\
-1 \\
\text { previously } \\
\text { known word }\end{array}$ & $\begin{array}{l}+4 \\
\text { new } \\
\text { words }\end{array}$ & -7 \\
\hline
\end{tabular}

While the weekly tests are informative about the progression of learning, the crucial point is how much of the learned vocabulary will be remembered over time. To measure this durable learning, a delayed posttest is required (Schmitt, 2010). In our 4-week delayed posttest, Neil checked and translated 20 words as opposed to 27 in week 8 , which means that he managed to retrieve nearly $75 \%$ of the words he had previously known. Extrapolating up to total gains, he potentially had durable learning of 83 words out of 112 words known at the end of the eighth viewing. Thus, in real terms, Neil learned 83 words out of 415 unknown words at the start of the study (20\%). This compares quite well to many studies of incidental vocabulary learning from reading (see Waring \& Takaki, 2003, Table 1 for an overview), especially for studies which required translation confirmation of learning and a long (3-month) delayed test: 4\% (Waring \& Takaki, 2003); 3\% (Brown, Waring, \& 
Donkaewbua, 2008). However, it must be remembered that this study investigated intentional learning, where Neil was supposed to notice unknown words in the subtitles, and pause/rewind to focus upon them. Whether one can consider a $20 \%$ learning rate positive or not, it depends largely on how efficient the learning was, i.e. the cost/benefit analysis of how many words were learned for the amount of time put into study.

\subsection{Rates of acquisition per viewing and per hour}

Table 2

Number of new words learned per viewing and learning rate per hour ${ }^{a}$

\begin{tabular}{|c|c|c|c|c|c|c|c|c|}
\hline $\begin{array}{l}\text { Week } 1 \\
2.5 \text { hours }\end{array}$ & $\begin{array}{l}\text { We } \\
5 \mathrm{~h}\end{array}$ & & $\begin{array}{l}\text { Week } 3 \\
7.5 \text { hours }\end{array}$ & $\begin{array}{l}\text { Week } 4 \\
10 \text { hours }\end{array}$ & $\begin{array}{l}\text { Week } 5 \\
12.5 \text { hours }\end{array}$ & $\begin{array}{l}\text { Week } 6 \\
15 \text { hours }\end{array}$ & $\begin{array}{l}\text { Week } 7 \\
17.5 \text { hours }\end{array}$ & $\begin{array}{l}\text { Week } 8 \\
20 \text { hours }\end{array}$ \\
\hline$/ \mathrm{h}$ & + & $/ \mathrm{h}$ & $/ \mathrm{h}$ & $/ \mathrm{h}$ & $/ \mathrm{h}$ & $/ \mathrm{h}$ & $/ \mathrm{h}$ & $/ \mathrm{h}$ \\
\hline 10.0 & 21 & 4.2 & 0 & 1.2 & 1.68 & .53 & .69 & 17 \\
\hline
\end{tabular}

Neil improved his test score by an average of 3.38 new word families per viewing (range 0-5), whilst consolidating previously known words. If we extend these test scores to the 415 unknown word families identified in the pretest, it means Neil acquired an average of around 14 new word families per viewing (Table 2). Although this is a lower rate than in Milton's (2008) experiment (40 lemmas per viewing ( $\approx 22$ families)), some of this difference can probably be explained by Milton's less rigorous vocabulary test (although his report is not explicit, it appears Milton used a checklist test without a translation confirmation).

By cumulating the number of hours spent on doing the activity week after week, we can get an estimate of how many new words Neil acquired per hour if we extend the results in Table 1 to the 415 unknown word families in the subtitles identified in the pretest. As shown in Table 2, the first viewing yielded a learning rate of 10 new words per hour, and this decreased by more than half in the second viewing to 4.2/hour. Even though Neil continued to learn new words in subsequent weeks, the fact that we need to cumulate the number of input hours from all previous weeks means that the learning rate per hour becomes very modest. Even though word knowledge was conceptualized in this study under very strict criteria, with only words which were given an exact translation counted as known, such a poor uptake rate suggests that after the first two viewings the activity was not very worthwhile and that time could have been far more efficiently used if Neil had learned the remaining words from other vocabulary activities. It might also be argued from this evidence that the most efficient method of using movies with reversed subtitles would be to watch each movie only once, as this is where the greatest uptake occurred. But even here, 10 words per hour is low compared to the learning rates from techniques like studying word cards $(\approx 30-100+$ words per hour; see Nation, 2001, pp. 297-299 for an overview). However, one must remember that learning words via films should lead to other benefits as well (e.g. learning words in context, fluency of reading, motivation), which might be seen to mitigate the lower learning rate to some extent.

\subsection{Impact of repetition on acquisition and retention}

Repetition/recycling has been shown to be an important factor in promoting vocabulary acquisition. To explore the role of repetition in audiovisual materials, I chose target words which occurred from 1-39 times in the film. I divided these words into three repetition categories: once, five times or fewer, and more than five times. I subsequently looked at these three categories at three points in the study: after the first, the fourth, and the eighth viewings (Table 3). 
Garnier, M.

Table 3

Percentage of words learned according to number of exposures after the first, fourth and eighth viewings

\begin{tabular}{llllllll}
\hline $\begin{array}{l}\text { Number } \\
\text { of word } \\
\text { families }\end{array}$ & Exposures & \% learned & Exposures & \% learned & Exposures & \% learned & Retrieve \% \\
\hline 44 & 1 & 2.3 & 4 & 13.6 & 8 & 20.5 & 18.2 \\
28 & $\leq 5$ & 7.1 & $\leq 20$ & 14.3 & $\leq 40$ & 42.9 & 25 \\
28 & $>5$ & 10.7 & $>20$ & 14.3 & $>40$ & 21.4 & 7.9 \\
\hline
\end{tabular}

The results from week 1 showed a very modest learning, which is in line with results from most incidental learning studies, but must be considered disappointing for an intentional learning technique. In terms of repetition, the expected relationship is found: more repetitions lead to more learning. By week 4 very similar results were found among the three repetition categories, which suggest that by the time words are met four times over a period of time, additional repetitions do little to improve learning. Week 8 shows the surprising result of similar percentages for words repeated 8 times and more than 40 times, with a percentage twice as high for words in between. Furthermore, 11 of the 100 target words were highly frequent in the film (10 to 39 times). But only four were rated as known by week 8 (although all of these were retrieved in the posttest). This suggests that some words remain unknown no matter how many times they are repeated. Even more unexpected are the posttest results where words repeated the greatest number of times had a very poor retrieval percentage as opposed to words repeated fewer times. Almost all the words repeated only 8 times and known in week 8 were remembered on the delayed posttest, as opposed to only about one-third of the words repeated more than 40 times.

So what are we to make of these results? First, in the initial viewing of a film, the amount of repetition does seem to matter, with more being better. However, with repeated viewings over four weeks, the effect of repetition seems to diminish after about 4 repetitions. Note that this was not the case in the initial viewing, but memory research has shown that distributed repetition (i.e. spaced over time) is more effective than massed repetition (i.e. all at one time) (Baddeley, Eysenck, \& Anderson, 2009). This suggests that there may be some sort of interaction between number of repetitions and the spacing of the repetitions. However, the small amount of case-study data makes it impossible to do more than raise this possibility. By week 8 , the relationship between number of repetitions and amount of learning seems to have completely broken down.

These findings are not in line with those from incidental learning studies, which generally show that words met 8-10 times have a much better chance of being learned than words met fewer times (e.g. Horst et al., 1998; Pellicer-Sánchez \& Schmitt, 2010). It seems that in intentional learning contexts such as this one, there are other factors which tend to override the effect of repetition frequency. Word class seems to be one: noticeably, a very large majority of the words which remained unknown were verbs. Furthermore, Neil made personal decisions about which subtitle words to stop and focus upon, and so salience, imageability, and meaningfulness in the context are likely to have had an effect on which words were learned and which were not. These are the types of word-based factors which Ellis and Beaton (1993) found influential in their study of foreign language vocabulary learning. But the learner characteristics also affect learning (i.e. individual differences, Dörnyei, 2005). Milton's (2008, p. 233) case study participant learned about twice as much vocabulary as Neil, but was characterized as being an "exceptionally good" learner who was "sufficiently highly motivated to spend many hours over several weeks engaged in [the learning] tasks". Conversely, Neil considered himself a very average learner who received unimpressive grades during his school instruction. Additionally, although he started with strong motivation, this faded over the weeks as the repeated viewings became more tedious. Likewise, it is unclear how well he was able to pay explicit attention to word forms in the subtitles. In the end, repetition is only one factor among many 
psycholinguistic and affective factors that influence learning, and in the case of film subtitles, it seems to be a less dominant one.

\subsection{The diary}

A close examination of Neil's diary resulted in three main observations. The first is that external factors such as tiredness and drop in motivation did have an impact on acquisition. As expected with such a repetitive activity, Neil's motivation dropped half way through the experiment. Secondly, a few practical disadvantages of the activity were mentioned, notably the speed of the subtitles which does not allow much time to notice word forms. Unless the learner takes the time to pause the film repeatedly, they are not likely to effectively remember many of the words in the subtitles. Thirdly, Neil provided an interesting explanation of his apparent difficulty to learn verbs. Since I had taken care to group all verb-endings included in the subtitles under their infinitive form on the test, Neil experienced some difficulty in matching the conjugated forms in the film to the infinitive forms on the test. From this, one limitation of a subtitle learning activity in French can be perceived: an instructed introduction to verb infinitives and verb endings would have been necessary beforehand.

\section{Conclusion}

The findings reveal that tangible vocabulary learning can be achieved from watching films in the reversed subtitling condition, and probably more than could be expected from a solely incidental learning approach. Moreover, because words known from previous viewings remained known on subsequent weekly tests (with one exception), and were remembered at a $75 \%$ rate on the 4-week delayed test, the activity appears to promote durable acquisition. However, a very poor learning rate per hour after the first two viewings suggests that such an activity is not worthwhile beyond a few hours spent on watching the same film. This study also showed that some words which were repeated a considerable number of times throughout the viewings were not acquired, and vice versa. Therefore, words need not be constantly repeated in the subtitles to be acquired, with some being acquired after only the first viewing. This means that learners can watch different films only once and potentially gain much from the experience - in this case 25 words from engaging with Toy Story 3 for 2.5 hours. But the characteristics of the unknown words (e.g. word class, salience) and individual learner attributes (e.g. motivation, language aptitude) may be more important to eventual learning than the simple frequency in which they are repeated in the films. This moderate influence of repetition is rather surprising, and in that sense is probably the most significant contribution of this study to understanding vocabulary acquisition through DVD-watching.

The main implications of the study for teachers and learners is that teachers should recommend this activity to their students as a useful supplement to formal instruction; and learners should benefit from engaging in regular DVD-watching as a means of learning new vocabulary in an enjoyable way. In every case, they should be explicitly encouraged to pay thorough attention to the subtitles and make pauses for taking notes or rewinding. However, formal and explicit instruction remains the most efficient route to learning - and retaining - new vocabulary.

From this single case-study of a British learner of French, it seems impossible to establish that DVD-watching in reversed subtitling conditions can be equally beneficial for learners of different L2s from different language backgrounds. Asian EFL learners, for instance, might experience difficulty with matching the L1 audio to the English words in the subtitles because word order might be different between their L1 and English. They may additionally experience more difficulty in following the subtitles than other learners whose L1 shares the same alphabet as English, whereas theirs uses logographic systems. A replication study involving Asian EFL learners would be very informative in this respect. Another limitation to the study is the fact that the number and duration of pauses made by the participant in each viewing was not controlled for. It might very well be that Neil made significantly more pauses in the first few viewings than in successive ones, which would explain why the latter were less fruitful - although he reported that total viewing times were similar. Controlling for this would no doubt be necessary in future replication. 


\section{Note}

I have respected my participant's request to use his real name in the present manuscript. My thanks go to Neil Patrick Milbourn and also to Professors James Milton and Norbert Schmitt for feedback during the study and write-up stage.

\section{References}

Baddeley, A., Eysenck, M.W., \& Anderson, M.C. (2009). Memory. Hove: Psychology Press.

Bisson, M.J., Van Heuven, W.J.B., Conklin, K., \& Tunney, R.J. (2012). Processing of native and foreign language subtitles in films: An eye-tracking study. Applied Psycholinguistics. http://dx.doi.org/10.1017/S0142716412000434

Brown, R., Waring, R., \& Donkaewbua, S. (2008). Comparing incidental vocabulary acquisition from reading, reading-while-listening, and listening to stories. Reading in a Foreign Language, 20(2), 136-163. The Compleat Lexical Tutor (version 6.1) Concordancer. (2013). http://www.lextutor.ca/

Danan, M. (1992). Reversed subtitling and Dual Coding Theory: New directions for foreign language instruction. Language Learning, 42(4), 497-527. http://dx.doi.org/10.1111/j.1467-1770.1992.tb01042.x

Dörnyei, Z. (2005). The Psychology of the Language Learner. Mahwah, NJ: Lawrence Erlbaum.

D’Ydewalle, G., \& Gielen, I. (1992). Attention allocation with overlapping sound, image, and text. In K. Rayner (Ed.), Eye Movements and Visual Cognition: Scene Perception and Reading (pp. 414-427). New York: Springer-Verlag. http://dx.doi.org/10.1007/978-1-4612-2852-3_25

D'Ydewalle, G., \& Pavakanun, U. (1995). Acquisition of a second/foreign language by viewing a television program. In P. Winterhoff-Spurk (Ed.), Psychology of media in Europe: The state of the art-perspectives for the future (pp. 51-64). Opladen, Germany: Westdeutscher Verlag GmbH. http://dx.doi.org/10.1007/978-3-322-94251-7_6

D'Ydewalle, G., \& Pavakanun, U. (1996). Does television subtitling facilitate language acquisition? [Le sous-titrage à la télévision facilite-t-il 1'acquisition des langues ?] In Y. Gambier (Ed.), Les transferts linguistiques dans les médias audiovisuels (pp. 217-223). Lille, France: Presses Universitaires du Septentrion.

D’Ydewalle, G., \& Pavakanun, U. (1997). Could enjoying a movie lead to language acquisition? In P. Winterhoff-Spurk \& T. Van der Voort (Eds.), New Horizons in Media Psychology (pp. 145-155). Opladen, Germany: Westdeutscher Verlag GmbH. http://dx.doi.org/10.1007/978-3-663-10899-3_10

D’Ydewalle, G., \& Van de Poel, M. (1999). Incidental foreign language acquisition by children watching subtitled television programs. Journal of Psycholinguistic Research, 28, 227-244.

Ellis, N.C., \& Beaton, A.A. (1993). Factors affecting the learning of foreign vocabulary: Imagery keyword mediators and phonological short-term memory. Quarterly Journal of Experimental Psychology, 46(3), 533-558. http://dx.doi.org/10.1023/A:1023202130625

Holobow, N.E., Lambert, W.E., \& Sayegh, L. (1984). Pairing script and dialogue: Combinations that show promise for second or foreign language learning. Language Learning, 34(4), 59-76. http://dx.doi.org/10.1111/j.1467-1770.1984.tb00352.x

Horst, M., Cobb, T., \& Meara, P. (1998). Beyond a clockwork orange: Acquiring second language vocabulary through reading. Reading in a Foreign Language, 11, 207-223.

Horst, M., \& Meara, P. (1999). Test of a model for predicting second language lexical growth through reading. The Canadian Modern Language Review, 56(2), 308-328. http://dx.doi.org/10.3138/cmlr.56.2.308

Hulstijn, J.H. (1992). Retention of inferred and given word meanings: Experiments in incidental vocabulary learning. In P.J.L. Arnaud \& H. Béjoint (Eds.), Vocabulary and Applied Linguistics (pp. 113-125). London: MacMillan.

Lambert, W.E., Boehler, I., \& Sidoti, N. (1981). Choosing the languages of subtitles and spoken dialogues for media presentations: Implication for second language education. Applied Psycholinguistics, 2, 133-148. http://dx.doi.org/10.1017/S0142716400000904 
Milton, J. (2008). Vocabulary uptake from informal learning tasks. Language Learning Journal, 36(2), $227-238$. http://dx.doi.org/10.1080/09571730802390742

Milton, J. (2009). Measuring Second Language Vocabulary Acquisition. Bristol: Multilingual Matters.

Nation, P. (2001). Learning Vocabulary in Another Language. Cambridge: Cambridge University Press. http://dx.doi.org/10.1017/CBO9781139524759

Paivio, A. (1986). Mental representations: A Dual-coding approach. New York: Oxford University Press.

Pavakanun, U., \& d'Ydewalle, G. (1992). Watching foreign television programs and language learning. In F.L. Engel, D.G. Bouwhuis, T. Bosser, \& G. d'Ydewalle (Eds.), Cognitive modeling and interactive environments in language learning (pp. 193-198). Berlin: Springer. http://dx.doi.org/10.1007/978-3-642-77575-8_24

Pellicer-Sánchez, A.M., \& Schmitt, N. (2010). Incidental vocabulary acquisition from an authentic novel: Do Things Fall Apart? Reading in a Foreign Language, 22, 31-55.

Saragi, T., Nation, P., \& Meister, G. (1978). Vocabulary learning and reading. System, 6, 72-80. http://dx.doi.org/10.1016/0346-251X(78)90027-1

Schmitt, N. (2010). Researching Vocabulary: A Vocabulary Research Manual. Basingstoke: Palgrave Macmillan. http://dx.doi.org/10.1057/9780230293977

Vanderplank, R. (1990). Paying attention to the words: Practical and theoretical problems in watching television programmes with uni-lingual (CEEFAX) sub-titles. System, 18(2), 221-234. http://dx.doi.org/10.1016/0346-251X(90)90056-B

Van Zeeland, H., \& Schmitt, N. (under review). Incidental vocabulary acquisition through L2 listening: $a$ dimensions approach.

Waring, R., \& Takaki, M. (2003). At what rate do learners learn and retain new vocabulary from reading a graded reader? Reading in a Foreign Language, 15, 130-163.

Winke, P., Gass, S., \& Sydorenko, T. (2010). The effects of captioning videos used for foreign language listening activities. Language Learning \& Technology, 14(1), 65-86. 
Garnier, M. 